\title{
Study on the Medical Security System in Rural and Pastoral Areas of Inner Mongolia Autonomous Region*
}

\author{
Chunfang HE \& Haihe JIN \\ School of Public Management, Inner Mongolia University, Hohhot, P.R. China
}

\begin{abstract}
At present, the framework of the medical security system in rural and pastoral areas of Inner Mongolia Autonomous Region has taken shape, which plays an important role in meeting needs of the farmers and herdsmen on health care and improving the health standard. First, this article elaborates on the operations of the medical security system in rural and pastoral areas of Inner Mongolia. And then, the problems that exist in the medical security system would be analyzed. Finally, combining with the real situation in Inner Mongolia, the proposals to improve the medical security system are offered so as to improve the medical service level in rural and pastoral areas and meet the needs of farmers and herdsmen on health care.
\end{abstract}

KEYWORD: NCMS (New Rural Cooperative Medical System); Medical Assistance; Public Health Services Farmers and Herdsmen; Inner Mongolia

\section{INTRODUCTION}

With the improving social security system, the medical and health services in China have made significant progress and besides, the medical security system for all citizens has been initially formed, including four levels, i.e., basic public health system, medical assistance system, health insurance system and supplementary medical security system.

Due to the limitations of objective conditions, such as the underdeveloped economy, adverse natural conditions and out-of-date information, the medical security system in rural and pastoral areas of Inner Mongolia is far from enough to meet the needs of farmers and herdsmen on medical security. In order to prevent farmers and herdsmen from falling into the endless loop from disease to poverty and vice versa and besides effectively solving the difficulty and lowering the high cost of medical treatment, the adjustment and improvement of medical security system in rural and pastoral areas should be facilitated. Only in this way can improve the health standard of farmers and herdsmen, promote economic and social development in those areas and meet the needs of farmers and herdsmen on medical security.

\section{PRESENT SITUATION OF MEDICAL SECURITY SYSTEM IN RURAL AND PASTORAL AREAS IN INNER MONGOLIA}

At present, the medical security system in rural and pastoral areas in Inner Mongolia is taken basic public health services as base, new rural and pastoral areas as the leading factor, rural medical assistance system as supplements and at last the medical insurance of serious illness of NCMS. And it aims at providing medical services for farmers and herdsmen and meeting the needs on healthy care.

\subsection{New System of Cooperative Medical Care in Rural and Pastoral Areas}

\subsubsection{Fund Raising and Fund Allocation}

The fund of new system of cooperative medical care in rural and pastoral areas consists of three parts, including financial support from central government, financial support from local government and individual payments of farmers and herdsmen[1]. Due to the different economic strength and population size and etc, the proportion of financing are different, but the difference is small. And the fund of NCMS is divided into four categories:

\footnotetext{
* Financed by the Major Project "Inner Mongolia Higher School of philosophy and social science research".

Project title: The path selection and policy design of overall development of urban and rural social security in Inner Mongolia. 
hospitalization fund, outpatient fund, insurance fund of serious illness and risk fund.

\subsubsection{Compensation Standard}

The compensation standard of NCMS includes hospitalization compensation and outpatient compensation. Taking Erdos City as an example:

\subsubsection{Hospitalization Compensation}

The limit line of hospitalization compensation (including special outpatient clinic) per capita every year is up to 200 thousand. And the compensation standard is as follows:

Table1 Hospitalization Compensation standard of NCMS

\begin{tabular}{|c|c|c|c|c|c|c|}
\hline \multicolumn{4}{|c|}{ Medical Institution } & \multirow[t]{2}{*}{ Pay- Line (Yuan) } & \multirow{2}{*}{$\begin{array}{l}\text { Compensation } \\
\text { Ratio }\end{array}$} & \multirow[t]{2}{*}{ Limt Line } \\
\hline \multicolumn{2}{|l|}{ Locality } & \multicolumn{2}{|l|}{ The Range of Hospital } & & & \\
\hline \multicolumn{2}{|c|}{ City, Village and County Level } & \multicolumn{2}{|c|}{ Sumu health clinics in towns and towships } & 200 & $90 \%$ & \multirow{6}{*}{200 thousand } \\
\hline \multirow{4}{*}{ City's Hospitals } & \multirow[t]{2}{*}{ Cla-ss I } & \multirow{2}{*}{$\begin{array}{l}\text { Under Second-class Hospita } \\
\text { (including second-class) }\end{array}$} & County Level & 400 & \multirow{2}{*}{$80 \%$} & \\
\hline & & & City Level & 600 & & \\
\hline & \multirow[t]{2}{*}{ Cla-ss II } & \multirow[t]{2}{*}{ Third-class Hospital } & County Level & 600 & \multirow{2}{*}{$75 \%$} & \\
\hline & & & City Level & 1000 & & \\
\hline \multicolumn{4}{|c|}{ Hospitals outside the city } & 1500 & $65 \%$ & \\
\hline
\end{tabular}

\subsubsection{Outpatient Compensation}

The designated medical institutions of outpatient compensation are Sumu health clinics in towns and townships in every country, community health service center and the clinics of Gacha villiage, which implements the integrated management of villages. The ratio of compensation is as follows:

Table2 Outpatient Compensation standard of NCMS

\begin{tabular}{|c|c|c|c|}
\hline \multirow{2}{*}{\begin{tabular}{|l|} 
Medical Institution \\
City's hospital of village and county level
\end{tabular}} & Pay Line (Yuan) & Compensation Ratio & $\begin{array}{l}\text { Limit Line } \\
\text { The limit line is set according to } \\
\text { the disease categories and } \\
\text { meanwhile, the total cost }\end{array}$ \\
\hline & 100 & $65 \%$ & \multirow{4}{*}{$\begin{array}{l}\text { The limit line is set according to } \\
\text { the disease categories and } \\
\text { meanwhile, the total cost } \\
\text { combining the limit line of } \\
\text { hospitalization can not exceed } \\
200 \text { thousand. }\end{array}$} \\
\hline \begin{tabular}{|l|l|}
$\begin{array}{l}\text { City's hospital (including } \\
\text { hospitals of district and city }\end{array}$ & $\begin{array}{l}\text { Under Second-class Hospital } \\
\text { (including second-class) }\end{array}$ \\
hos
\end{tabular} & 300 & $55 \%$ & \\
\hline Third-class Hospital & 500 & $45 \%$ & \\
\hline Hospitals outside the city & 700 & $35 \%$ & \\
\hline
\end{tabular}

\subsection{Rural and Pastoral Medical Assistance System}

The fund of rural and pastoral medical assistance system is from government allocations and voluntary contributions of all sectors of society. And the target people are including five guarantees family with serious illness, poor households and entitled groups in rural areas. And the four assistance measures consist of regular medical assistance, medical assistance for serious illness, outpatient assistance for serious illness and temporary medical assistance.

\subsection{Basic Public Health Services}

The meaning of basic public health services covers a lot. And here, the author refers to the narrowly meaning of public health service, of which the content is providing the disease control and prevention and maternal and child protection. The major institution responsible for the public health services is Sumu health clinics in towns and townships. Until 2010, the number of health clinics in towns and townships in Inner Mongolia is 1340, of which the number of beds is 16424.[2]And Sumu health clinics in towns and townships provides various public health services, including building health records of farmers and herdsmen, popularizing the common sense of health care, executing the national immunization plan, vaccinating, registering and reporting the infectious disease and suspected cases within the region and controlling epidemics.

\subsection{Medical Insurance of Serious Illness of NCMS}

Since 2014, Inner Mongolia has already carried out the work of medical insurance of serious illness of NCMS, of which the target people are the farmers and herdsmen who are insured that very year. And the insurance coverage is the annual large amount of fees of certain serious disease. And the specific compensation coverage and standard is consulted to the municipal administrative department of NCMS. And 20 yuan per person from the collective funds of NCMS is taken as the insurance expense and no additional fee should be paid. Besides, the annual ratio of fund surplus for commercial insurance companies cannot be over $5 \%$. The part in excess of $5 \%$ should return to the fund of NCMS. If the proportion of capital loss of commercial insurance for serious illness is below $10 \%$, the insurance companies should bear the cost and as for the part in excess of 
$10 \%$, the cost of $40 \%$ of the excessive part should be borne by NCMS and the rest cost should be borne by commercial insurance companies.

\section{PROBLEMS THAT EXIST IN THE MEDICAL SECURITY SYSTEM}

Today, the medical security system in rural and pastoral areas is relatively well-developed and to the larger extent, can meet the needs of farmers and herdsmen on medical care. However, there still exist some problems. This article would analyze it from four aspects.

\subsection{Poor Propaganda of Policy and Unfamiliar with Medical Security Policy}

In the rural and pastoral areas, there are many reasons, which make farmers and herdsmen be unfamiliar with medical security policies.[3]First, due to the low education and poor democratic awareness of leaders in Gacha village committee, it is difficult to understand and deliver the policy in time, which thus has an impact on the delivery of policies and the normal operations of mechanism. Second, due to the specificity of the geographical conditions in pastoral areas, the residence dispersal leads to the difficulty of delivering the policies correctly and immediately in an objective way. At last, the Internet penetration is still very low and the poor infrastructure of information networks is still a problem. Besides, the communication technology has not yet been used widely. All the reasons mentioned above make farmers and herdsmen be unfamiliar with the current policy and they also do not know how to guarantee their rights.

\subsection{Limited Medical Service of Health Clinics in towns and townships and the Shortage of Health Care Supply}

The shortage of health care supply in health clinics in towns and townships is as follows. First, currently, the medical professionals are significantly insufficient in health clinics in towns and township in rural and pastoral areas. Second, rural and pastoral areas are severely short of medical health resources. Besides, the shortage of medical health resources limits the offering of medical health services to farmers and herdsmen. Third, because of the specificity in rural and pastoral areas, the residence dispersal, isolated information and inconvenient traffic, farmers and herdsmen cannot see the doctors or be vaccinated in Sumu health clinics in towns and townships without delay and thus the popularity of medical health services is lowered.

\subsection{Single type of compensation in NCMS}

Although the NCMS shares large medical expense with farmers and herdsmen, it still cannot meet the needs on disease prevention and disease rehabilitation. The compensation of NCMS only consists of hospitalization compensation and outpatient compensation, which does not include the medical expenses related to disease prevention and rehabilitation.[4]Therefore, if farmers and herdsmen need a further examination, they have to go to the medical institutions with higher level and the high costs for the low-income farmers and herdsmen are unaffordable. As a result, due to the high expenses of examination and rehabilitation, which cannot be claimed by NCMS, it results in the limitation of the needs on disease prevention and rehabilitation of lowincome farmers and herdsmen.

\section{PROPOSALS TO IMPROVE THE MEDICAL SECURITY SYSTEM IN RURAL AND PASTORAL AREAS OF INNER MONGOLIA}

In order to provide better medical health services for farmers and herdsmen and improve the overall health standard of farmers and herdsmen, and thus stimulate the social and economic development, it is necessary to supply and adjust the current mechanism of medical security. And this article would analyze it from four aspects.

\subsection{Do More Publicity and Implement All the Policies without Delay}

In order to ensure that all the farmers and herdsmen know medical policies well, first, leaders in Gacha Village should be aware of the importance of policy advocacy and implement policies of superior government without delay. And then, leaders should make full use of various means to improve the awareness of policies. First is to actively promote the activities, such as delivery of policy to each household, which is to deliver related promotional materials to every household. And second is to arrange a liaison in each village, who is responsible for supervise the publicity in every village. And at last, supervision should be strengthened and the implementation of policies should be promoted.

\subsection{Promote the Compensation Mechanism of NCMSG}

\subsubsection{Disease Prevention and Rehabilitation should be included in the Scope of Reimbursement of NCMS}

To meet the needs of farmers and herdsmen on disease prevention and rehabilitation and improve the quality of medical service, the costs of disease prevention and rehabilitation should be included in the scope of reimbursement of NCMS. And the ratio 
of reimbursement for medical expenses of disease rehabilitation can be decided according to the age, labor capacity, family economic conditions as well as local fiscal capacity. And how to implement this policy needs to be further discussed.

\subsubsection{Mongolian Medicine and Traditional Chinese Medicine should be encouraged in Medical Security System}

If the insured people of NCMS and other medical insurances see doctors in designated medical institutions of Mongolian and traditional Chinese medicine, the pay line of reimbursement is lowered by $20 \%$ to $50 \%$. And the reimbursement ratio would increase by $15 \%$ to $20 \%$ based on the former fundament, of which the maximum can not exceed 95\%. And many characteristic treatment technology of Mongolian and traditional Chinese medicine should be included in the hospitalization reimbursement. The traditional method should be taken as priority and besides, the treatment expenses of patent medicine, preparations, decoction pieces of Mongolian and traditional Chinese medicine, costs of boiling medicine, expenses of syndrome differentiation and prescription dispensing and other expenses of appropriate technology and traditional therapy, all these mentioned should be included in the scope of NCMS.

\subsection{The role of mobile health stations and the small medicine chest should be given into full play}

In rural and pastoral areas, mobile health stations and the small medicine chests play an important role in meeting the medical needs of farmers and herdsmen, but in practice, some still do not fulfill the goals. Therefore, it is necessary to improve the service of mobile health stations and the small medicine chests. First, through improving the infrastructure construction and training of medical workers, the service level of mobile health would be improved. And then, the coverage of "small medicine chests" in rural and pastoral areas should be promoted, and it should be promoted in all the areas of Inner Mongolia.

\subsection{The group of country doctors should be stabilized and strengthened}

The training system of doctors should be standardized and the training of general practitioners should be strengthened. And all the available resources should be used in training the medical talents. Medical practitioners should be arranged to go to the jobtransfer training of general practitioners. And the reform pilots of professional way of general practitioners and service mode should be promoted. And the supervision and evaluation of pilots should be started. And high-level talents should be introduced. And the reform of educational reform should be deepened. And the regulatory mechanism combining the medical talents training with the development of medical health system should be built. And the program of inheriting traditional Chinese medicine and cultivating innovative talents should be implemented.

\section{CONCLUSION}

Based on the analysis of the current situation of medical security system in rural and pastoral areas in Inner Mongolia, the author analyzes the problems that exist in the system. And combining the current situation in Inner Mongolia, the author provides some proposals to improve the medical security system.

(1) To improve the democratic awareness of leaders in Gacha village. To improve the knowledge of medical security policies by means of assigning liaisons in each Gacha village, delivering promotional materials, holding variety show.

(2) To invest more for the health clinics in Sumu towns and townships, expand the construction scope of health clinics and improve the medical service level.

(3) To improve the compensation mechanism of NCMS by two methods. One is that the disease prevention and rehabilitation should be included in the scope of reimbursement of NCMS and another is that the service of Mongolian and traditional Chinese medicine should be encouraged in medical security system.

(4) To improve the professional skills of doctors in mobile medical service station and improve the medical equipments in service station. And "small medical chests" should be carried out in Inner Mongolia.

(5) To deepen the reform of medical education, strengthen the training of general practitioners and democratic doctors, regulate the current training system of doctors and introduce high-level medical talents.

\section{REFERENCES}

[1] Zheng Gongcheng. 2011.The reform and development strategy of social security in China-medical securit.Beijing :People's Publishing House.

[2] Editorial Committee of Inner Mongolia statistical yearbook. Inner Mongolia Statistical Yearbook2011.Beijing: China statistical Publishing House.

[3] Qiu Yulin.2008.MedicalInsurance.Beijing:China Labour \& S ocial Security Publishing House.

[4] An Hua. 2012.8. The research on the social security in minority areas-based on the research on four minority inhabitations with small population size in Inner Mongoli.Insurance Studies. 